\title{
RISKY SHIFT AS A FUNCTION OF GROUP MEMBERS' VALUE OF RISK AND NEED FOR APPROVAL ${ }^{1}$
}

\author{
HELMUT LAMM,² EDITH SCHAUDE, AND GISELA TROMMSDORFF \\ University of Mannheim, West Germany
}

\begin{abstract}
Eighty-eight female subjects were assigned to dyads homogeneously composed with regard to their valuation of risk acceptance (low or high) as well as their need for approval (low or high). The dyads discussed each of a set of hypothetical decision situations involving risk taking and, at the end of each discussion, indicated the risk levels acceptable for them. High-value dyads shifted significantly more toward risk, relative to their prior decisions $(2 \times 2$ analysis of variance). As intended, the study demonstrates that risk as a value plays a causal role in the group risky-shift effect. Other results are brought to bear on the parsimony of recent formulations of the value theory of risky shift.
\end{abstract}

"Value theory" explains the group riskyshift phenomenon as a consequence of the positive value typically placed on risk acceptance, in conjunction with group discussion as a vehicle for attaining the value (Brown, 19.65)..$^{3}$

Levinger and Schneider (1969) have shown the first supposition-that risk is a value-to be true. When asked about the level of risk acceptance that they considered as most admirable, college students indicated higher levels of risk than they had accepted in their own previous decisions. (It was anticipated that the same would be found in the present study.) Additional support comes from a study by Madaras and Bem (1968), who found more positive evaluations (ratings) being made of risk-accepting than of cautious stimulus persons.

Even with the evidence just noted, it remains to be demonstrated that the positive value of risk acceptance is a causal factor

1 This research is part of the program of the Research Center for Social and Economic Psychology (Sonderforschungsbereich) at the University of Mannheim and was financed by the Deutsche Forschungsgemeinschaft.

2 Requests for reprints should be sent to Helmut Lamm, Institut fur Sozialwissenschaften, Universitat Mannheim, 68 Mannheirn, West Germany.

${ }^{3}$ No consideration will be given here to the reported finding of cautious shifts on a few items (hypothetical decision situations) of the kind used in the present study as a measure of risk taking. Just as it can be argued that value theory is able to account for shifts toward lower risk levels, so the argument of the present study can be applied, by appropriate inversion, to the (less general) phenomenon of a group shift toward caution. underlying the group risky-shift effect. The present study is intended to establish this causality by showing that groups of subjects placing high value on risk acceptance manifest larger risky shifts than groups characterized by lower valuation of risk.

Just as the existence of the nexus between the value of risk and the shift toward risk has not been empirically established, so its nature -the social-motivational process bringing about the risky-shift outcome--has not been investigated conclusively. A formulation that is attractive by its applicability beyond the risk-taking domain has been proposed by Levinger and Schneider (1969), who found that subjects typically consider themselves as more willing than their peers to accept risk. This finding has been reported in other recent studies (Ferguson \& Vidmar, 1970; Stoner, 1968; Wallach \& Wing, 1968), and the present study was designed to confirm it with German subjects. As Levinger and Schneider (1969) suggested, discussion provides a new (more risky) reference point to group members, who are thus "freed to make a new compromise between their ideal and the newly perceived point of reference, and their choices can shift closer to their ideal [p. 168]." That the reference point (estimate of peers' risk acceptance) indeed changes toward higher risk levels as a result of discussion has been shown by Ferguson and Vidmar (1970).

Two questions may be raised in regard to the above considerations. First, is the shift in reference point-the "eye-opener" effect-essential to the validity of the value theory? 
Brown (1965, p. 705) himself has suggested another mediating mechanism, invoking the bias in discussion content presumably taking place as arguments are selected and formulated by discussion participants. (This proposition can be subsumed under the biasing effect of values on the perception of ambiguous stimuli. In the present case, the risk value would bias the cognitions-the discussion points-elicited by the choice-dilemmas situations.) It is hoped that the present study will shed some light on the above question.

Second, what motivations underlie the desire, acted out through group discussion, to move closer toward ideal positions (higher risk levels)? Conceivably, the approximate attainment of ideal standards serves a need for social recognition or approval. To explore this possibility, the present study investigates the role of subjects' needs for social approval. According to Crowne and Marlowe (1964), "the studies of the approval motive suggest a set of self-reflexive attitudes-a self conception-in which an idealized version of the self . . is maintained and defended [p. 190]." It may be hypothesized that groups of subjects characterized by high approval needs, compared to groups with low approval needs, would shift more markedly toward higher risk acceptance, because they would thereby move toward more highly regarded positions. ${ }^{4}$ Confirmatory results on this hypothesis would suggest that one motivational factor involved in the group shift mechanism is the desire for esteem. The inclusion of need for approval as an experimental variable was frankly exploratory, particularly in view of its complexity as a personality construct (see Crowne \& Marlowe, 1964, p. 201) and in view of Kogan and Wallach's (1967) finding of a negative association between need for approval and risky shift $(p<.09)$.

\footnotetext{
4 It is assumed here-but not crucial to our main argument-that subjects, on decisions they themselves consider as ideal (deserving of highest regard), believe the ideal preferences of their peers to be in the same-more risky-direction. This assumption is easy to test. To have pertinent data collected from the subjects of the present experiment would have made them possibly too sensitive to the purposes of the study.
}

\section{Subjects}

\section{Method}

One bundred and fifty-five female students at the University of Mannheim (Germany) volunteered to participate. On the basis of the preexperimental measures (see below), 88 subjects were selected to take part in the experiment proper, for which they were paid.

\section{Risk-Taking Instrument}

The choice-dilemmas task (Kogan \& Wallach, 1964, Appendix E) was used to measure risk taking. Items 6 and 12 were omitted, and the remaining items were translated and adapted to fit the German cultural context (see Lamm \& Kogan, 1970). Each item presents a hypothetical decision situation as might accur in everyday life, in which a protagonist has to choose between a relatively unattractive but safe course of action and a more attractive but risky alternative (e.g., carrying on with a heart ailment versus undergoing an operation). The level of risk taking is indicated by the minimum odds of success considered necessary for choosing the risky alternative. The 10-point risk-taking scale ranges from a $10 \%$ to a $100 \%$ chance that the risky alternative would be successful.

\section{Preexperimental Session}

The preexperimental session constituted in essence a replication of the three choice-dilemma measures obtained by Levinger and Schneider (1969)--(a) own decisions, $(b)$ estimate of peer decisions, and (c) ideal decisions. Between 10 and 20 subjects participated in these sessions at a time. All assignments were carried out individually. (a) For each item, the subjects indicated the minimum odds they considered necessary before recommending the choice of the risky alternative. (b) They were then asked to go through the choice dilemmas again and indicate, for each item, the response they thought would be given by the majority of German students of their own sex. In other words, they noted down the minimum odds of success presumably chosen by most of their peers. (c) Finally, they were asked to go through the items a last time and indicate the decisions for which they had the highest regard ("Ihre höchste Anerkennung finden würde").$^{5}$

\footnotetext{
5 The present study used a weaker term than Levinger and Schneider's (1969) "most admirable," in order to reduce the possibility of a semantic demand factor. More concretely, the term "admirable" would, by its mere comnotational meaning, seem to be less applicable to a cautious decision than would the phrase "deserving of high regard." Thus, the present measure of risk as a value is, if anything, more conservative than the one of Levinger and Schneider (1969).
} 
TABLE 1

Means for Initial and Experimental Samples as Charactertzed BY CONTROL AND INDEPENDENT VARIABLES

\begin{tabular}{|c|c|c|c|c|}
\hline Variable & $\begin{array}{l}\text { Low value } \\
(N=44)^{\mathrm{a}}\end{array}$ & $\begin{array}{l}\text { High value } \\
(N=44)^{3}\end{array}$ & $\begin{array}{l}\text { Whole sampleb } \\
\qquad(N=88)\end{array}$ & $\begin{array}{c}\text { Initial sample } \\
(N=155)\end{array}$ \\
\hline $\begin{array}{l}\text { Own decisions } \\
\text { Low need for approval } \\
\text { High need for approval } \\
\text { Peer minus own } \\
\text { Low need for approval } \\
\text { High need for approval } \\
\text { Value (own minus ideal)e } \\
\text { Low need for approval } \\
\text { High need for approval } \\
\text { Need for approvale } \\
\text { Low need for approval } \\
\text { High need for approval }\end{array}$ & $\begin{array}{l}48.59 \\
47.27 \\
\\
6.00^{* *} \\
7.54^{* *} \\
2.82 \\
4.64^{* *} \\
11.36 \\
18.77\end{array}$ & $\begin{array}{l}48.59 \\
48.64 \\
6.45^{*} \\
9.82^{* *} \\
18.32^{* * *} \\
19.36^{* * *} \\
11.27 \\
18.64\end{array}$ & $\begin{array}{l}48.27 \\
7.54^{* * * *} \\
11.28^{* * * *}\end{array}$ & $7.30^{* * * *}$ \\
\hline
\end{tabular}

- Twenty-two subjects low and 22 subjects high in need for approval.

b Experimental sample.

- Higher scores indicate lower risk levels.

d No significant effects $(F<1)$ for either independent variable.

* Independent variable.

$* p<.05$ (two-tailed $i$ test).

*** $p<.01$ (two-tailed $t$ test).

$* * * *<.001$ (two-tailed $i$ test).

As a last assignment, the subjects filled out a German translation of Crowne and Marlowe's (1964) need-approval (or social-desirability) questionnaire.

\section{Independent Variables and Assignment to Experimental Conditions}

The value attached to risk taking was operationalized as the extent to which the subjects placed the ideal at a rishier level than their own decisions. On the basis of this own-versus-ideal discrepancy score, the 155 subjects of the total sample were classified, by median split, as low or as high on the value dimension (see Table 1).

Again by a median split on the total distribution, the subjects were classified as low or high on need for approval as measured by the Crowne-Marlowe scale (see Table 1).

Since higher risk valuation was associated with lower own risk levels $(r=.29$, df $=153, p<.01)$, and since group risky shift could not be assumed to be independent of own (prior) risk levels, the selection of subjects from the total sample was restricted by the requirement of keeping own risk decisions equal over the four experimental conditions (see Table 1).

\section{Procedure}

The dyadic discussions took place a few weeks after the preexperimental session. Upon arrival at the laboratory, each subject received an instruction sheet and a booklet containing the choice-dilemmas descriptions.

The instructions asked the two participants to discuss each of the familiar decision situations, and at the end of a discussion, indicate their decisions (minimum odds of success considered necessary for choosing the risky alternative). For the latter, they could draw on the considerations brought out during the discussion. Though each member should make her own decision, the exchange of views could of course lead to a consensus. It was further pointed out that the discussions would be tape recorded to be played later to a group of coeds. They could be sure of anonymity throughout those replays. (The instructions revolving around the tape recordings were intended to provide a rationale for the dyadic discussions. In addition, the mention of a future audience was intended to induce a sense of a larger group presence.)

The subjects were asked to discuss each item thoroughly before making their decisions but to take no more than 5 minutes for each item. The female experimenter noted down the decisions announced at the close of a discussion. If the latter had to be broken off because the time limit was reached, the experimenter asked the participants to state their decisions in alternating order.

\section{RESUlts}

Oren, Peer, and Ideal Decisions and Their Interrelations in the Initial Sample

Table 1 shows that the subjects ascribed more cautious decisions to their peers, relative to their own decisions $(p<.001)$. As is further evident from Table 1 , the decisions held in highest regard (ideal decisions) were located at higher risk levels than the subjects' own decisions $(p<.001)$.

The following correlational results were obtained by computing a correlation coefficient for each of the 10 items, resulting in an 
"average" $r$ after appropriate $z$ transformations. Significant positive correlations $(p<$ .01 or better) were found between own and peer, own and ideal, and peer and ideal decisions ( $r=.41, r=.52, r=.26$, respectively). Further, a significant negative correlation was found between peer-minus-own and ownminus-ideal decisions $(r=-.34, p<.01)$, indicating that the more the subject assumes she is riskier than her peers, the smaller the distance she indicates between her own actual and her ideal decisions. In other words, the more the subject thinks she excels her peers in risk acceptance, the more she considers herself as being in line with her ideal. (It may be of interest to note that this correlation did not approach significance when computed on total choice-dilemmas scores.)

None of the correlations between need for approval and the variables mentioned above (based on total choice-dilemmas scores) approached significance.

\section{Results Involving Risky Shift}

As is shown in Tables ? and 3, subjects characterized by a higher value of risk (higher discrepancy between own and ideal, more risky decisions) manifested larger risky shifts after dyadic discussion than those in the low value category $(F=4.46, p<.05)$, confirming the principal experimental hypothesis.

With the exception of the low-value, highneed-approval condition, the risky shifts were significant for the various dyadic types $(p<$ .05 or better; see Table 2 ).

In addition to the analyses presented in Tables 2 and 3, correlations were performed between the own-peer discrepancy score and risky shift. The correlation was not significant when based on total choice-dilemmas scores. But when performed on each of the items, the 10 coefficients yield an average $r$ of $-.31(p<.01$, after appropriate $z$ transformations). In other words, the more pronounced the tendency to see oneself as riskier than the peer group, the smaller the shift toward higher risk levels. This result, surprising at first glance in its apparent contradiction to the value-theory prediction, becomes more plausible when one considers, on the one hand, the positive correlation $(r=$
TABLE 2

Means and Standard Deviations on Dyadic Risky Shift

\begin{tabular}{|c|c|c|c|c|}
\hline \multirow{2}{*}{ Item } & \multicolumn{2}{|c|}{ Low value } & \multicolumn{2}{|c|}{ High value } \\
\hline & $\bar{X}^{3}$ & SO & $\bar{X}^{a}$ & $S D$ \\
\hline Low need for approval & 2.09 & 9.90 & $8.45^{*-\pi}$ & 5.89 \\
\hline High need for approval & $3.77 *$ & 4.69 & $5.27^{* *}$ & 7.70 \\
\hline
\end{tabular}

Note.-Eleven dyads per cell.

T Total choice-dilemmas shift, per individual.

$\begin{aligned} & * p<.05 \text { (two-tailed). } \text {. } \\ & * * * 0.01 \text { (two-tailed). }\end{aligned}$

$.32, d f=86, p<.01$ ) between own predyadic decisions and risky shift (i.e., more cautious subjects shifted more markedly) and, on the other hand, the negative correlation $(r=-.39, d f=86, p<.01)$ between own predyadic decisions and relative underestimation of peers' risk acceptance (i.e., the more cautious subjects were less likely to believe their peers to be more cautious than themselves). When own predyadic decisions are partialed out, the resulting partial correlation between relative underestimation of peers' risk acceptance and risky shift becomes negligible. When based on dyadic scores $(N$ $=44$ ), the correlation is negligible even without partialing out subjects' own predyadic decisions. The above correlational patterns are the same (though at lower levels of significance) for each of the four experimental conditions (22 subjects in each case).

\section{Discussion}

The finding of Levinger and Schneider (1969) --that subjects think they accept more risk than their peers and that, on the other hand, they accept less risk than they consider ideal-is replicated here with German subjects, thus confirming the validity of the central and a subsidiary assumption contained in

TABLE 3

ANALYsis of VARIANCE

\begin{tabular}{l|r|r|r}
\hline \multicolumn{1}{c|}{ Source } & $d f$ & \multicolumn{1}{c|}{ MS } & \multicolumn{1}{c}{$F$} \\
\hline Value (A) & 1 & 170.05 & $4.46^{*}$ \\
Need for approval (B) & 1 & 6.19 & .16 \\
A X B & 1 & 48.64 & 1.27 \\
Error & 40 & 38.17 & \\
\hline
\end{tabular}

$* p<.05$. 
the value theory of the risky-shift phenomenon.

More important, the present study provides a direct and successful test of the proposition that the risky-shift effect is indeed a function of risk as a value. ${ }^{6}$ This causal relation has heretofore not been empirically demonstrated.

No evidence was found concerning any effect on risky shift of the subjects' underestimation of their peers' (relative to their own) risk acceptance. However, with mere two-person groups, the present experiment may have provided a rather inefficient design for uncovering any effect of the peer-estimation factor: it is doubtful that a single peer-group member's display of higher than expected risk acceptance has sufficient impact to change one's reference point in the risky direction. It may be concluded, then, that the present design has been too weak to allow the socialcomparison factor (peer estimation) of the value theory to come into play. Stronger experimental procedures (larger sized groups and direct manipulation) are needed to investigate that factor as a possible contributor to the risky-shift effect. On the other hand-and more important at this point--considering that the value of risk did have the predicted effect on risky shift in the present study, one is led to conclude that the socialcomparison component (underestimation of peers) is not necessary for value theory to be valid.

The approval motive had no effect on risky shift. In explanation, consider that the need for approval may motivate subjects to present themselves as in line with normal standards (see Crowne \& Marlowe, 1964, p. 202) as

- Vidmar (1970) has shown that greater heterogeneity (discrepancy) among group members' initial choice-dilemmas decisions is associated with greater risky shift. To ascertain whether the present riskyshift differences were not caused by such differential heterogeneity, an approximative index of heterogeneity was obtained for each of the four sets of experimental dyads by computing, for each item, the standard deviation of own decisions over the respective 22 individuals. The low-and high-value conditions did not differ on that index. The average (per item) standard deviations were 1.95, 2.01, 1.94, and 1.97 for the low-low, low-high, high-low, and high-high value and need-approval conditions, respectively. well as with ideal standards of behavior (Crowne \& Marlowe, 1964, p. 190; Pervin \& Lilly, 1967). In the present experimental situation, these two orientations may be seen as represented by the respective measures of peer-own and own-ideal position discrepancies. Obviously, the two tendencies here act in mutually opposite directions. Thus, if in the present study the subjects high, in comparison to those low, in need for approval strive more strongly to match ideal standards (higher risk levels), the effect is neutralized by their stronger concern over closeness to the presumed normal position (lower risk levels). If the latter consideration is valid, high approval needs should be associated with stronger shifts in sufficiently large groups, where group discussion demonstrably leads to the displacement of the perceived social standard toward higher risk (Ferguson \& Vidmar, 1970 ), thus "taking care" of subjects' concern over closeness to the normal position. Yet, Kogan and Wallach (1967), using fiveperson female groups, found an indication of smaller shifts by groups of subjects high in need for approval. (These authors explained their finding through the affective inhibitions presumably characterizing persons with strong approval needs.)

Concerning the role of the approval motive, it may thus be concluded that the present study-together with Kogan and Wallach (1967)-casts doubt on the desire for social esteem as a possible motivational source underlying subjects' shift toward more aspired and risky stands. Rather, it appears to be self-esteem motivation that disposes subjects toward greater commitment to their aspired risk levels. The latter proposition is supported by a near-significant correlation $(r=.25$, df $=42, p<.10$, two-tailed) between self-esteem and risky shift across the 44 experimental dyads. ${ }^{\tau}$ (No other correlation with self-esteem approached significance.) The role of self-esteem in risky shift appears to be worth more focused investigation.

7 A German version of Cohen's (1953) self-esteem scale, measuring self- versus ideal discrepancies, was administered at the end of the experimental session. Thus, an interesting possibility remains that risky shift raises participants' self-esteem. 
The implications of the present study may be summarized as follows: (a) It is demonstrated conclusively that the group risky-shift effect is attributable, at least in part, to the positive value of risk. The principal argument of value theory is thus confirmed by experimental evidence. (b) There is indirect evidence in the present study suggesting that the social-comparison aspect of value theory - the fact that subjects typically think they surpass their peers in risk acceptance is less essential to the validity of value theory than has been widely assumed. (c) Tentative evidence suggests that shifting toward risk in a group discussion helps subjects sustain their self-esteem rather than gain social esteem. This is presumably because they are moving closer to a position which they personally value.

\section{REFERENCES}

Brown, R. Social psychology. New Yark: Free Press of Glencoe, 1965.

Comes, A. R. The effects of situational structure and individual self-esteem on threat-oriented reactions to power. Unpublished doctoral dissertation, University of Michigan, 1953.

Crowne, D. P., \& Martowe, D. The approval motive: Studies in evaluative dependence. New York: Wiley, 1964.
Ferguson, D. A., \& VIDMar, N. Effects of group discussion on culturally appropriate risk levels. (Res. Bull. No. 135, Department of Psychology) London, Ontario: University of Western Ontario, 1970.

KogAN, N., \& WALLACH, M. A. Risk taking: A study in cognition and personality. New York: Holt, Rinehart \& Winston, 1964.

KogAN, N., \& WaLlaCH, M. A. Group risk taking as. a function of members' anxiety and defensiveness levels. Journal of Personality, 1967, 35, 50-63.

LAMLM, H., \& KoGAv, N. Risk taking in the context. of intergroup negotiation. Journal of Experimental Social Psychology, 1970, 5, 351-363.

Levinger, G., \& SchNerder, D. J. Test of the "risk is a value" hypothesis. Journal of Personality and Social Psychology, 1969, 11, 165-169.

Madakas, G. R., \& Beir, D. J. Rish and conservatism in group decision-making. Journal of $E x-$ perimental Social Psychology, 1968, 4, 350-365.

Pervin, L. R., \& LLLY, R. S. Social desirability and self-ideal self-ratings on the semantic differential. Educational and Psychological Measurement, 1967, $27,845-853$.

STONER, J.A. F. Risky and cautious shifts in group decisions: The influence of widely held values. Journal of Experimental Social Psychology, 1968, 4, 442-459.

VIDMar, N. Group composition and the risky shift. Journal of Experimental Social Psychology, 1970, 6, 153-166.

Wallach, M. A., \& Wing, C. W., JR. Is risk a value? Joumal of Personality and Social Psychology, 1968, 9, 101-106. 